\title{
PROBABILIDADE DE OCORRÊNCIA DO Ca E Mg FOLIAR EM LAVOURA DE MAMÃO
}

\author{
Danielle Inácio Alves ${ }^{1}$ \\ Walas Permanhane Sturião ${ }^{2}$ \\ Julião Soares de Souza Lima ${ }^{3}$ \\ Samuel de Assis Silva ${ }^{4}$
}

Resumo: Objetivou-se neste trabalho, estudar a distribuição espacial do Ca e Mg do pecíolo do mamoeiro por meio de krigagem indicativa. As folhas (pecíolo), recém-maduras, foram coletadas em uma lavoura comercial de mamão localizada no norte do Estado do Espírito Santo, sendo os pontos amostrados definidos em uma malha amostral georreferenciada. Após coleta e processamento do material em laboratório foi realizada a análise descritiva e geoestatística dos dados. A krigagem indicativa foi usada para estimar a probabilidade de ocorrência do Ca e do Mg na lavoura e como ponto de corte utilizaram-se os níveis considerados adequados para a cultura. Ambos nutrientes apresentaram valores abaixo do nível adequado para a cultura, podendo ser observado também nos mapas de distribuição, onde a maior parte da área apresentou valores abaixo do nível adequado. Por meio dos mapas gerados é possível a realização da fertilização com Ca e Mg de forma diferenciada na área, aplicando-se o fertilizante apenas nas áreas com baixa ocorrência do nutriente foliar.

Palavras-chave: Carica papaya L.; Geoestatística; Análise foliar.

\footnotetext{
1 Estudante do Programa de Pós-Graduação em Produção Vegetal/Universidade Federal do Espírito Santo, Brasil. E-mail: danielle.inacio@hotmail.com.

2 Estudante do programa de Pós-Graduação em Fitotecnia/Universidade Federal de Viçosa, Brasil. E-mail: agro_es@hotmail.com

3 Professor de Agronomia/Universidade Federal do Espírito Santo, Brasil. E-mail: limajss@yahoo.com.br.

${ }^{4}$ Professor de Agronomia/Universidade Federal do Espírito Santo, Brasil. E-mail: sasilva@pq.cnpq.br.
} 